\title{
OPEN Development of phenotypic assays for identifying novel blockers of L-type calcium channels in neurons
}

\author{
Rebecca Hagan ${ }^{1}$, Elizabeth Rex², David Woody², Monika Milewski², Thomas Glaza², \\ Michael P. Maher ${ }^{1} \&$ Yi Liu $^{1 \bowtie}$
}

L-type calcium channels (LTCCS) are highly expressed in the heart and brain and are critical for cardiac and neuronal functions. LTCC-blocking drugs have a long and successful record in the clinic for treating cardiovascular disorders. In contrast, establishment of their efficacy for indications of the central nervous system remains challenging given the tendency of existing LTCC drugs being functionally and mechanistically more selective for peripheral tissues. LTCCs in vivo are large macromolecular complexes consisting of a pore-forming subunit and other modulatory proteins, some of which may be neuro-specific and potentially harbor mechanisms for neuronal selectivity. To exploit the possibility of identifying mechanistically novel and/or neuro-selective blockers, we developed two phenotypic assays-a calcium flux-based primary screening assay and a patch clamp secondary assay, using rat primary cortical cultures. We screened a library comprised of 1278 known bioactive agents and successfully identified a majority of the potent LTCC-blocking drugs in the library. Significantly, we identified a previously unrecognized LTCC blocker with a novel mechanism, which was corroborated by patch clamp and binding studies. As such, these phenotypic assays are robust and represent an important step towards identifying mechanistically novel and neuro-selective LTCC blockers.

L-type calcium channels (LTCCs, a.k.a. $\mathrm{Ca}_{\mathrm{V}} 1$ ) belong to a family of voltage-gated calcium channels (VGCCs), which selectively permit $\mathrm{Ca}^{2+}$ ions into cells upon opening in response to membrane depolarization. LTCCs (predominantly $\mathrm{Ca}_{\mathrm{V}} 1.2$ and $\mathrm{Ca}_{\mathrm{V}} 1.3$ ) are widely expressed and serve critical functions in both brain and heart/ vasculature $^{1}$. Gain-of-function mutations in $\mathrm{Ca}_{\mathrm{V}} 1.2$ and $\mathrm{Ca}_{\mathrm{V}} 1.3$, for example, can lead to Timothy syndrome ${ }^{2}$ (with multiorgan dysfunction, including prolonged QT, cardiac arrhythmias and autism) and neurodevelopmental or endocrine symptoms ${ }^{3} . \mathrm{Ca}_{\mathrm{V}} 1.2$ and $\mathrm{Ca}_{\mathrm{V}} 1.3$ are also implicated in psychiatric and neurological disorders such as bipolar disorder, major depression and Parkinson's disease ${ }^{4,5}$.

Drugs that block LTCCs for the treatment of cardiovascular disorders such as hypertension and arrhythmia have seen successful clinical use for decades ${ }^{6}$. In contrast, establishment of the clinical efficacy of LTCC-blocking drugs remains challenging for disorders of the central nervous system (CNS), such as bipolar disorder ${ }^{7}$. One hypothesis holds that such drugs (even those that are highly CNS penetrant) may not reach therapeutic concentrations in the brain at therapeutic dosages for treating cardiovascular diseases ${ }^{6}$. Although all known LTCC drugs bind to the pore region of $\alpha 1$ subunits, functional potency in vivo appears to vary substantially in the brain and cardiovasculature. Indeed, binding of these drugs to LTCCs is state dependent, favoring open ${ }^{8,9}$ (e.g., verapamil and diltiazem) and/or inactivated ${ }^{8,10,11}$ (e.g., dihydropyridines, or DHPs) states, conditions that are more readily encountered in cardiovascular tissues than in the brain. Thus, current LTCC drugs may be functionally biased for cardiovascular indications, limiting their therapeutic utility for CNS indications.

VGCCs in vivo are large macromolecular signaling complexes consisting of a central pore-forming $\alpha 1$ subunit surrounded by multiple auxiliary subunits (e.g., $\beta$ and $\alpha 2 \delta$ ) and other interacting/modulatory proteins. A recent study in cardiomyocytes showed that a large variety of proteins lie within the $\mathrm{Ca}_{\mathrm{V}} 1.2$ channel subdomain ${ }^{12}$. A study of $\mathrm{Ca}_{\mathrm{V}} 2$ channel nano-environments similarly revealed that $\mathrm{Ca}_{\mathrm{V}} 2$ channels are embedded into protein networks that may be assembled from a pool of a large number of proteins ${ }^{13}$. A number of studies have characterized regulatory proteins that biochemically and/or functionally interact with neuronal LTCCs ${ }^{14-22}$. In addition,

${ }^{1}$ Neuroscience Discovery, Janssen Research \& Development, L.L.C, 3210 Merryfield Row, San Diego, CA 92121, USA. ${ }^{2}$ Discovery Sciences, Janssen Research \& Development, L.L.C, 3210 Merryfield Row, San Diego, CA 92121, USA. ${ }^{\circledR}$ email: yliu10@its.jnj.com 
a

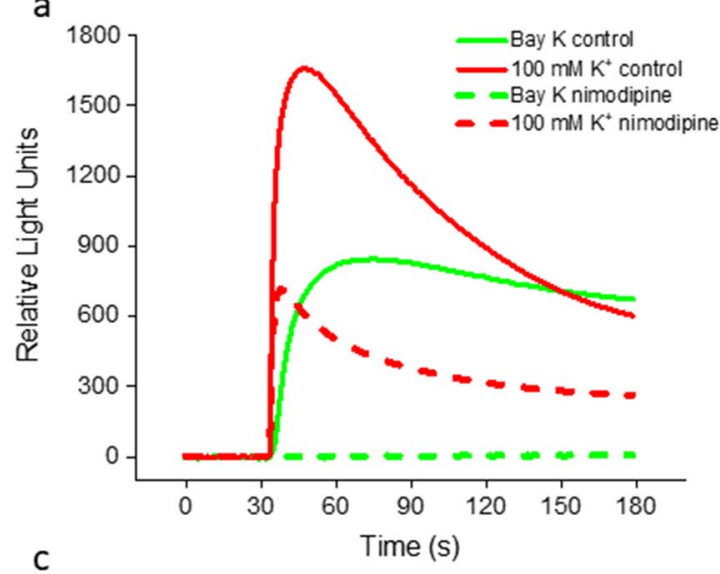

C

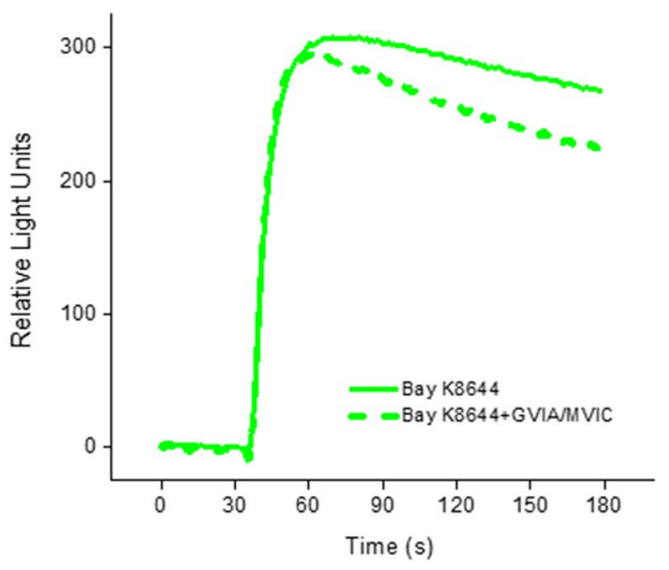

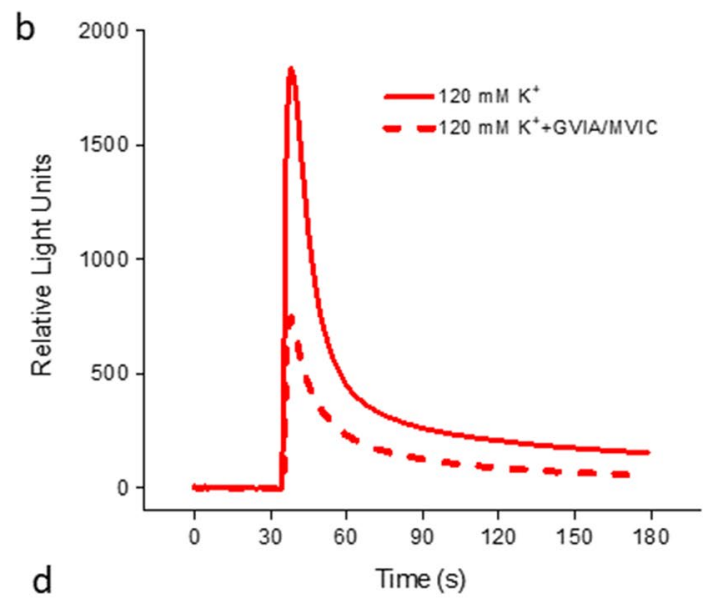

d

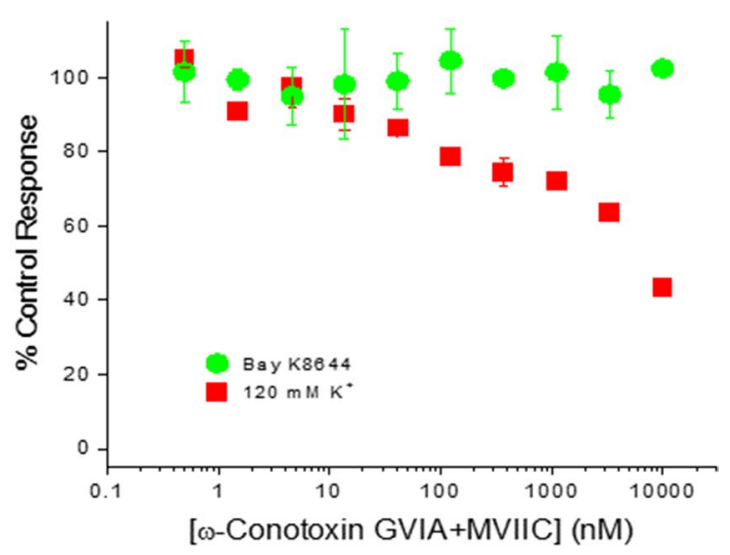

Figure 1. Functional expression of LTCCs and other VGCCs in rat cortical cultures. (a) Calcium fluorescent responses to stimulation by high $\left[\mathrm{K}^{+}\right](100 \mathrm{mM}$; solid red line) and Bay K8644 (1.1 $\mu \mathrm{M}$; solid green line). Nimodipine $(3 \mu \mathrm{M})$ partially (dashed red line) and completely (dashed green line) inhibited the high $\left[\mathrm{K}^{+}\right]$- and Bay K-evoked responses, respectively. (b) Calcium fluorescent responses evoked by high $\left[\mathrm{K}^{+}\right](120 \mathrm{mM}$; solid line) were partially blocked by a cocktail of VGCC (but not LTCC) blockers (dotted line), $\omega$-conotoxin GVIA (N-type) and $\omega$-conotoxin MVIIC (N-, P- and Q-types), both at $10 \mu \mathrm{M}$. (c) Calcium fluorescent responses evoked by Bay K8644 (300 nM; solid line) were not sensitive to the cocktail (dotted line). (d) Concentration dependence of the cocktail effects on high $\left[\mathrm{K}^{+}\right]$- and Bay K-induced responses. Summary of 4 independent experiments like those in (b) and (c). The holding $\left[\mathrm{K}^{+}\right]$was $20 \mathrm{mM}$ in all experiments.

various spliced variants of $\mathrm{Ca}_{\mathrm{V}} 1.2$ have also been identified ${ }^{23}$, some of which may be more neuronally enriched and confer distinct physiological and pharmacological properties ${ }^{5,24}$. Variant isoforms of LTCC genes can lead to changes in channel properties ${ }^{24-26}$. Therefore, it is conceivable that LTCCs in neurons may confer novel and/ or neuro-selective pharmacological properties through neuro-favoring/specific interactions.

In this study, we took a phenotypic approach to screening for novel, neuro-selective LTCC blockers. Using primary cultures of rat cortical neurons, we developed two phenotypic assays, a fluorescence-based mediumthroughput screening assay and a secondary patch clamp confirmation assay. We conducted a primary screen of 1278 commercially available small molecule drugs and other bioactives, which successfully identified majority of the LTCC drugs, lending validation to these assays. Importantly, we identified a novel, potent LTCC blocker, suggesting the utility of this approach towards identifying novel and neuro-selective LTCC modulators.

\section{Results}

Isolation of LTCC-mediated responses in rat primary cortical cultures. Cortical neurons express LTCCs as well as other VGCCs. As shown in Fig. 1a, application of $100 \mathrm{mM} \mathrm{K}^{+}$evoked a large calcium fluorescent response in a rat primary cortical culture that was partially blocked by nimodipine $(3 \mu \mathrm{M})$, a potent and selective LTCC antagonist, indicating that LTCCs represented a substantial fraction of VGCCs expressed in these cultures. Elevated concentrations of $\mathrm{K}^{+}$indiscriminately activate all VGCCs. To selectively activate LTCCs, we used Bay K8644, a LTCC-selective agonist, to stimulate responses in these cultures. In contrast to $100 \mathrm{mM} \mathrm{K}^{+}$, the Bay K8644 (1.1 $\mu \mathrm{M}$ )-induced response was completely blocked by $3 \mu \mathrm{M}$ nimodipine (Fig. 1a), indicating that it was LTCC mediated. To better understand whether the Bay K-induced response was a result of direct calcium influx through LTCC channels or due to secondary activation of other VGCCs, we included two VGCC- (but not LTCC-) blocking peptides, $\omega$-conotoxin GVIA (N-type calcium channel blocker) and $\omega$-conotoxin MVIIC (Nand P/Q-type calcium channel blocker). As shown in Fig. 1b-d, the peptide cocktail partially blocked the high 

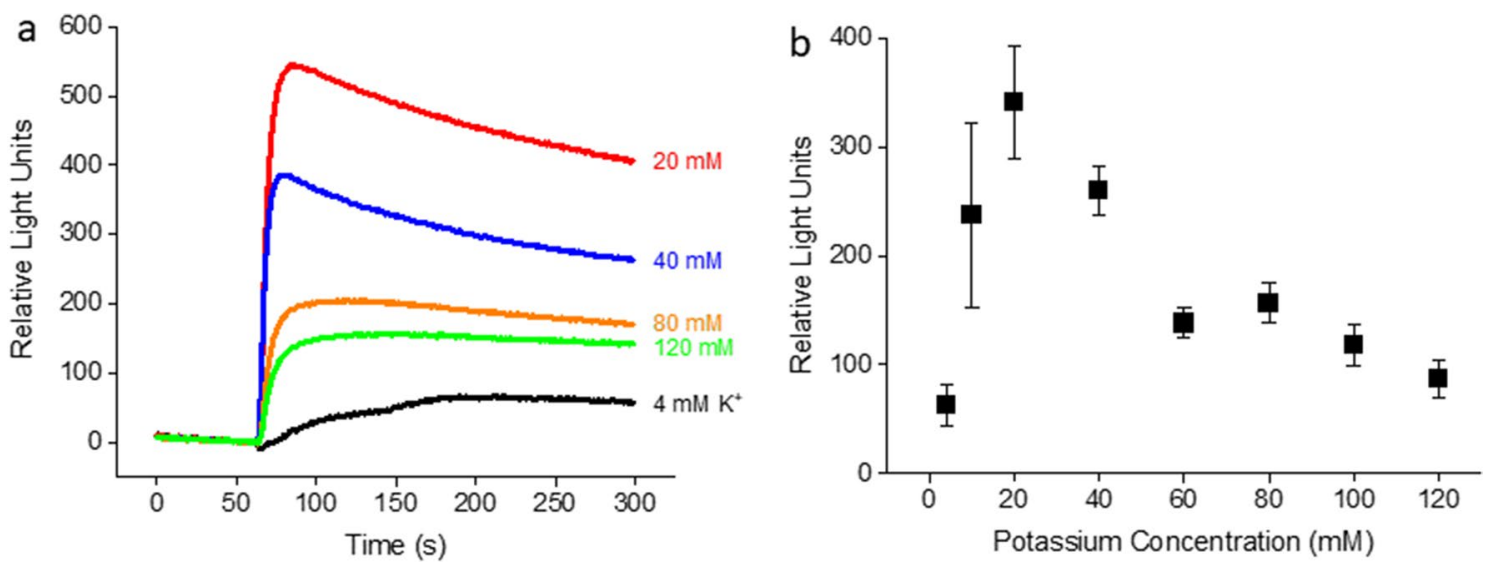

Figure 2. $\left[\mathrm{K}^{+}\right]$dependence of fluorescent responses to Bay K8644 $(300 \mathrm{nM})$ in rat cortical cultures. (a) Traces of calcium fluorescence for a range of $\mathrm{K}^{+}$concentrations as indicated. Each $\left[\mathrm{K}^{+}\right]$used during Bay $\mathrm{K}$ application was the same as that used for preincubation of cells. (b) Summary of experiments $(n=10)$ similar to (a).

$\left[\mathrm{K}^{+}\right]$-induced response in a concentration-dependent manner, but had little effect on Bay K-induced response, indicating that the Bay K-induced response was due to direct calcium influx through LTCCs.

Optimization of the phenotypic fluorescence assay. Bay K8644 potentiates LTCCs by shifting the voltage dependence of channel activation towards hyperpolarized membrane potentials ${ }^{27}$. Consequently, the amplitude of Bay K-evoked response is dependent on the resting membrane potential. Significant responses appear only when the resting membrane potential is depolarized sufficiently close to the threshold for LTCC activation. To maximize Bay K-evoked responses, we varied the resting membrane potential by preincubating cells with a range of holding $\mathrm{K}^{+}$concentrations. As shown in Fig. 2, Bay $\mathrm{K}(300 \mathrm{nM})$-induced responses as a function of holding $\left[\mathrm{K}^{+}\right] \mathrm{s}$ were bell-shaped, peaking at $20 \mathrm{mM}$ holding $\left[\mathrm{K}^{+}\right]$, which corresponds to a resting membrane potential of roughly $-50 \mathrm{mV}$. At this membrane potential, T-type calcium channels are inactivated, preventing potential contamination by non-specific responses from this class of VGCCs. Together with the finding that the Bay K-induced responses at $20 \mathrm{mM}$ holding $\left[\mathrm{K}^{+}\right]$were LTCC specific (Fig. 1), we chose to preincubate cells in a buffer containing $20 \mathrm{mM} \mathrm{K}^{+}$in our assay.

We also studied the effects of several other parameters on Bay K-evoked responses, including cell density, tolerance for DMSO and culture days in vitro (DIV). The results are either shown in Supplementary Fig. S1 and Fig. S2 or described in Methods section. The values for these parameters used in the screening assay are given in the Methods section.

Pharmacology of reference compounds. Next, we evaluated the LTCC pharmacology in the calcium flux assay using reference compounds that are well described in the literature. Bay K potently activated LTCCs with an $\mathrm{EC}_{50}$ of $203.9 \mathrm{nM}$ (Fig. 3a,b). The three major classes of LTCC antagonists, nimodipine (a DHP), verapamil (a phenylalkylamine) and diltiazem (a benzothiazepine) concentration-dependently inhibited $300 \mathrm{nM}$ Bay K-induced responses with $\mathrm{IC}_{50}$ values of $142.4 \mathrm{nM}, 18.5 \mu \mathrm{M}$ and $27.1 \mu \mathrm{M}$, respectively (Fig. 3c,d), in general agreement with the literature ${ }^{28-30}$. Taken together, our phenotypic calcium flux assay showed convincing hallmarks of LTCC specificity.

Prestwick library screen. To further validate and test the robustness of the assay, we performed a pilot screen of 1278 known bioactive small molecules from the Prestwick (PW) library. Compounds were screened at a single concentration $(3 \mu \mathrm{M})$ in duplicates and percent inhibition values were calculated for each compound. The Z' value for the screen was $0.52 \pm 0.11$ (mean \pm SD). The correlation between two independent runs was 0.62 with a slope of 0.71 (Fig. $4 \mathrm{a}$ ), suggesting reasonable reproducibility. The histogram of the mean $\%$ inhibition showed a major peak centered near zero (mean $\pm \mathrm{SD}=-7.8 \pm 22.5 \%$ ) and a second, smaller population with greater \% inhibition values (Fig. $4 \mathrm{~b}$ ). We set the cutoff value at $70 \%$ based on these data, resulting in the selection of 75 candidate hits (5.9\% of the compounds screened) for confirmation in a concentration-response format. Sixty of them $(80 \%)$ were confirmed with $\mathrm{IC}_{50}$ values $<5 \mu \mathrm{M}(\mathrm{n}=3)$. The profile of the confirmed hits is summarized Fig. 4c.

DHPs are a major class of LTCC-blocking drugs and are well represented in the PW library (12 DHPs). Ten of the 12 DHPs (83.3\%) were successfully identified in the top 75 hits from the screen, all of which were among the top 20 confirmed hits with highest potencies. At least six of the remaining 10 non-DHPs in the top 20 hits, cyproheptadine $^{31}\left(\mathrm{IC}_{50}=138 \mathrm{nM}\right.$ from the screen), GBR $12909^{32}(680 \mathrm{nM})$, lidoflazine ${ }^{33}(710 \mathrm{nM})$, fluspirilene ${ }^{34}$ $(760 \mathrm{nM})$, fendiline $\mathrm{e}^{35}(820 \mathrm{nM})$, and clomipramine ${ }^{36}(1010 \mathrm{nM})$, have been reported in the literature to potently block LTCCs. In the top 10 confirmed hits listed in Table 1, eight are DHPs and two (niclosamide and cyproheptadine) are non-DHPs. To our knowledge, niclosamide (an anthelmintic; $80 \mathrm{nM}$ ) is the only compound in Table 1 for which no published information is available about the effect on LTCCs. Using a separately validated patch clamp assay, we confirmed the LTCC-blocking activity of niclosamide in rat cortical neurons (see below). 
a

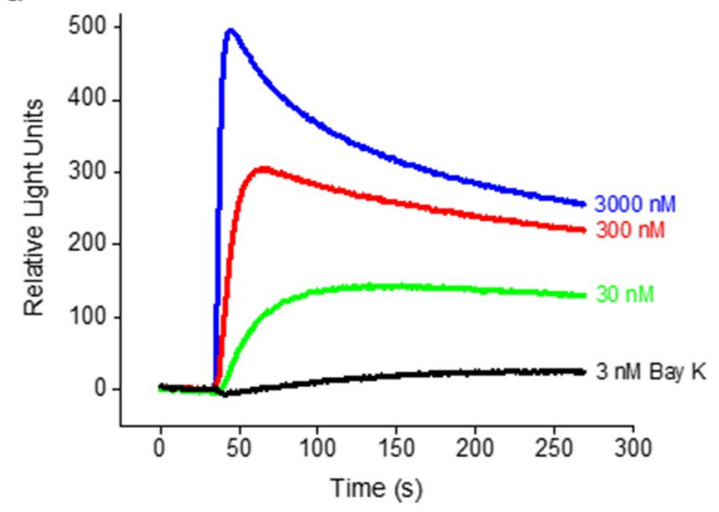

C

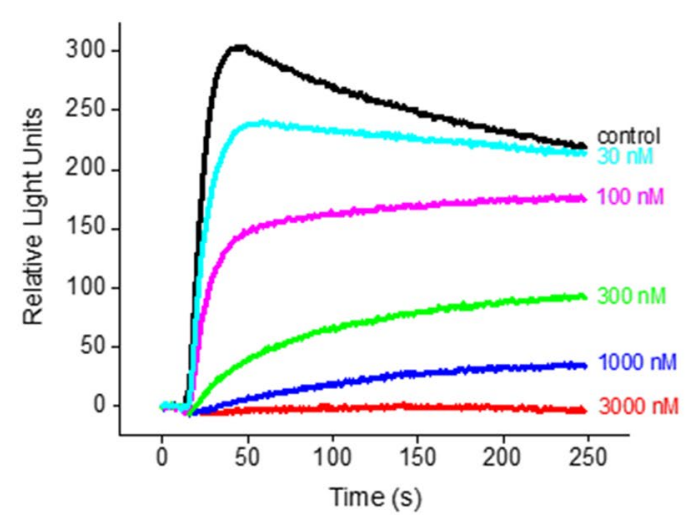

b

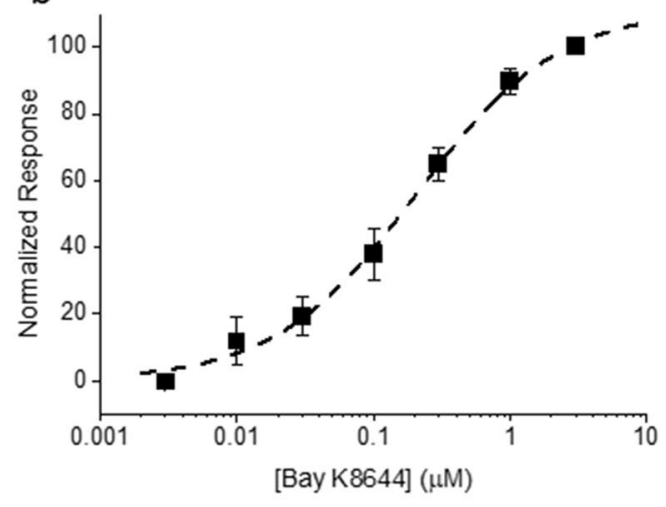

d

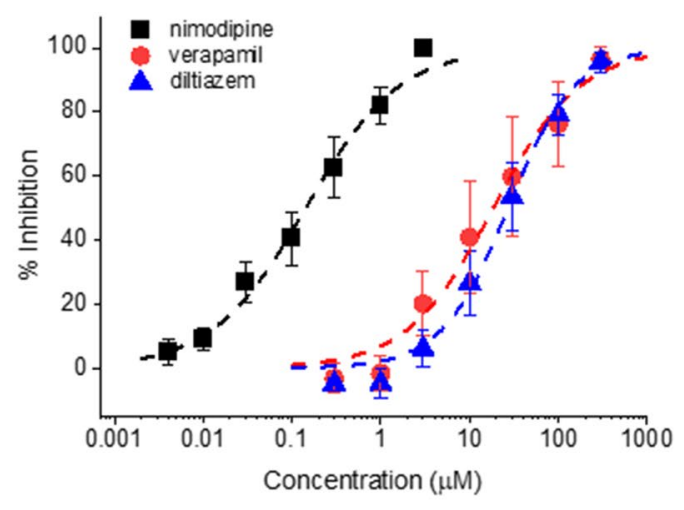

Figure 3. LTCC pharmacology from rat cortical cultures. (a) Fluorescent responses to a range of Bay K8644 concentrations. (b) Summary of Bay K concentration dependence for seven independent experiments similar to (a). $\mathrm{EC}_{50}=203.9 \mathrm{nM}$ from the best fit (dashed curve) to the data. (c) Fluorescent responses to Bay K8644 for a range of nimodipine concentrations. (d) Summary of concentration dependence data for multiple experiments for nimodipine, verapamil and diltiazem. The $\mathrm{EC}_{50}$ values from the best fits (dashed curves) to the nimodipine $(n=12)$, verapamil $(n=4)$ and diltiazem $(n=6)$ data were $142.4 n M, 18.5 \mu M$ and $27.1 \mu M$, respectively. The concentration of Bay $\mathrm{K} 8644$ was $300 \mathrm{nM}$ in (c) and (d). The holding $\left[\mathrm{K}^{+}\right]$was $20 \mathrm{mM}$ in all the experiments.

In conclusion, the phenotypic calcium flux assay was robust and validated by its ability to identify most of the known LTCC blockers as well as a novel LTCC blocker in the PW library.

Development of a secondary patch clamp assay. We also developed and validated a secondary patch clamp assay using rat cortical neurons to confirm hits identified from the calcium flux assay. The buffers used in patch clamp were intended for isolating/maximizing calcium channel responses (substituting extracellular $\mathrm{Ba}^{2+}$ for $\mathrm{Ca}^{2+}$ ) and minimizing/eliminating sodium and potassium channel activity (extracellular choline replacing $\mathrm{Na}^{+}$and intracellular $\mathrm{Cs}^{+}$replacing $\mathrm{K}^{+}$). They simultaneously served to abolish network activities normally present in neuronal cultures without the need to introduce cocktail inhibitors of synaptic activity. To obtain conditions optimized for LTCC currents, we varied the holding $(-90 \mathrm{mV}$ or $-50 \mathrm{mV})$ and testing $(-20 \mathrm{mV}$ or $0 \mathrm{mV}$ ) potentials. As shown in Fig. 5a, the fraction of nimodipine-sensitive current was lower when holding/ testing the cell at $-90 / 0 \mathrm{mV}(75 \%)$ or at $-50 / 0 \mathrm{mV}(85 \%)$ compared to the $-50 /-20 \mathrm{mV}$ protocol (96\%). Importantly, inclusion of $300 \mathrm{nM}$ Bay K (a near-saturating concentration; Fig. 5b) in the extracellular solution greatly amplified the LTCC currents (Fig. 5c,d) and effectively reduced the fraction of nimodipine-insensitive (i.e., nonLTCC) currents (as seen in Fig. 5a from the $99 \%$ block by nimodipine in the presence of Bay K). As expected, Bay K decreased the potency of nimodipine inhibition by 16.7 fold $\left(\mathrm{IC}_{50}\right.$ was increased from $24.8 \mathrm{nM}$ in the absence of Bay K to $414.6 \mathrm{nM}$ in the presence of Bay K; Fig. 5a), consistent with the two DHPs competing for the same binding site ${ }^{37}$. In addition, the potency of nimodipine block was also decreased at the holding potential of $-90 \mathrm{mV}\left(\mathrm{IC}_{50}=4.8 \mu \mathrm{M}\right.$; Fig. 5a), in agreement with the well-documented voltage dependence of DHP blockers ${ }^{8}$.

Under the optimized recording conditions (i.e., with the $-50 /-20 \mathrm{mV}$ protocol in the presence of Bay $\mathrm{K}$ ), a cocktail of VGCC- (but not LTCC-) blocking peptides had little effect (11\% inhibition) on $\mathrm{Ba}^{2+}$ currents (Fig. 5e). By contrast, the same cocktail blocked a significantly higher fraction $(56 \%)$ of $\mathrm{Ba}^{2+}$ currents under conditions in which other VGCCs were allowed to contribute to the current (i.e., with the $-90 / 0 \mathrm{mV}$ protocol in the absence of Bay K; Fig. 5e). Taken together, results in Fig. 5 demonstrated that the chosen recording solutions, inclusion 
a

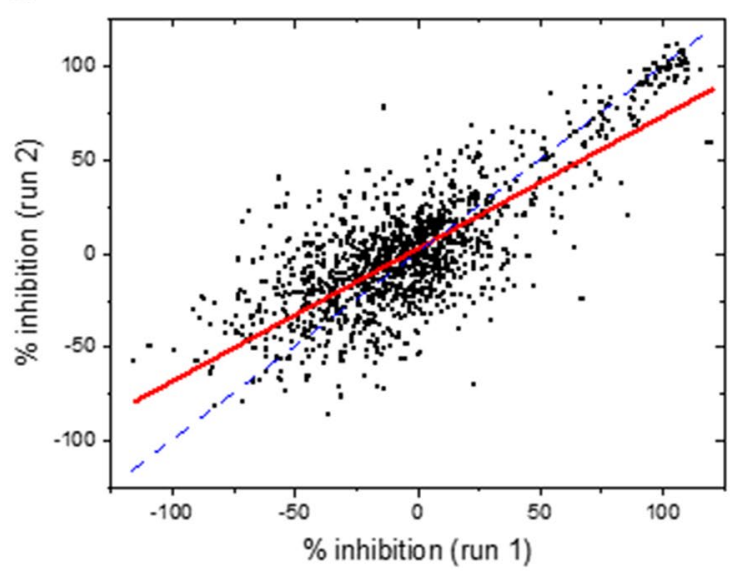

C

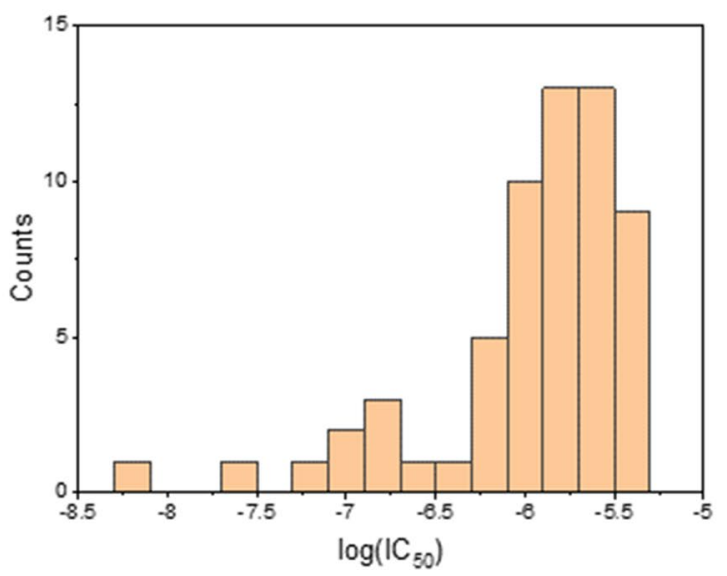

b

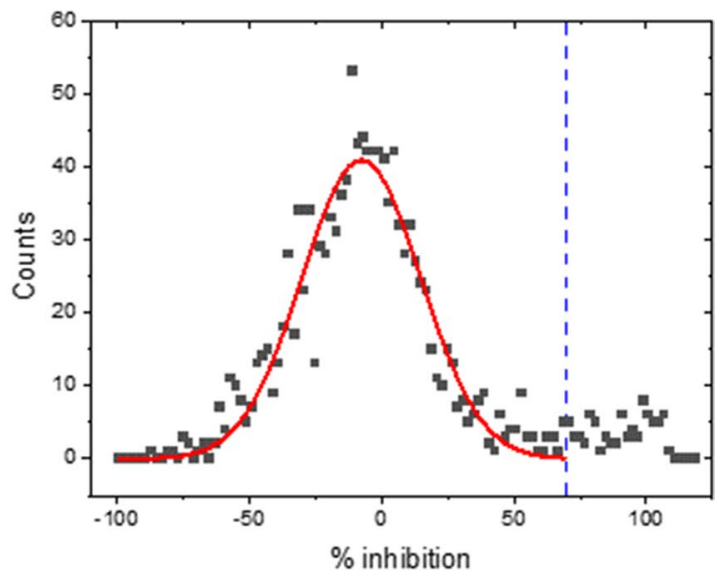

Figure 4. Results of the Prestwick library screen. (a) Correlation of two independent runs for each compound (test concentration $=3 \mu \mathrm{M}$ ). Two compounds with large fluorescent artifacts are omitted. The solid red line is the linear least-squares fit $\left(\mathrm{r}^{2}=0.62\right.$; slope $\left.=0.71\right)$. The dashed blue line is the line of identity. (b) Histogram of the mean \% inhibition. The bin size is $2 \%$. Data with \% inhibition $<70 \%$ (left of the dashed blue line) are fitted to a Gaussian function (solid curve; mean $\pm \mathrm{SD}=-7.8 \pm 22.5 \%$ ). (c) Potency histogram of confirmed hits from the PW screen. The bin size is 0.2 .

\begin{tabular}{|c|c|c|c|c|c|c|}
\hline \multirow[b]{2}{*}{ Drug Name } & \multirow{2}{*}{$\begin{array}{l}\text { FLIPR IC50 (nM) } \\
\text { Rat cortical culture }\end{array}$} & \multirow[b]{2}{*}{ Chemical Class } & \multicolumn{3}{|c|}{ Rat cortex binding $\mathrm{Ki}(\mathrm{nM})$} & \multirow[b]{2}{*}{$\begin{array}{l}\text { References (LTCC } \\
\text { block) }\end{array}$} \\
\hline & & & DHP site & $\begin{array}{l}\text { Phenylalkylamine } \\
\text { site }\end{array}$ & $\begin{array}{l}\text { Benzothiazepine } \\
\text { site }\end{array}$ & \\
\hline Isradipine & 8 & DHP & & & & $\begin{array}{l}\text { Balasubramanian } \\
\text { et al., } 2009\end{array}$ \\
\hline Nilvadipine & 28 & DHP & & & & Ishibashi et al., 1997 \\
\hline Felodipine & 57 & DHP & & & & Angus et al., 2000 \\
\hline Niclosamide & 80 & Non-DHP & $>30,000$ & $>30,000$ & $>30,000$ & \\
\hline Benidipine & 104 & DHP & & & & Nishiya et al., 2002 \\
\hline Nimodipine & 110 & DHP & & & & Xia et al., 2004 \\
\hline Cyproheptadine & 138 & Non-DHP & 3562 & 3303 & 2278 & Winquist et al., 1984 \\
\hline Nitrendipine & 140 & DHP & & & & Xia et al., 2004 \\
\hline Nicardipine & 290 & DHP & & & & Xia et al., 2004 \\
\hline Lacidipine & 453 & DHP & & & & Xia et al., 2004 \\
\hline
\end{tabular}

Table 1. Top 10 primary hits from the PW library by potency. $\mathrm{IC}_{50}$ values $(\mathrm{nM})$ are from the phenotypic calcium flux assay using rat cortical cultures. $\mathrm{K}_{\mathrm{i}}$ values $(\mathrm{nM})$ are from binding studies using rat cortical homogenates. 
a

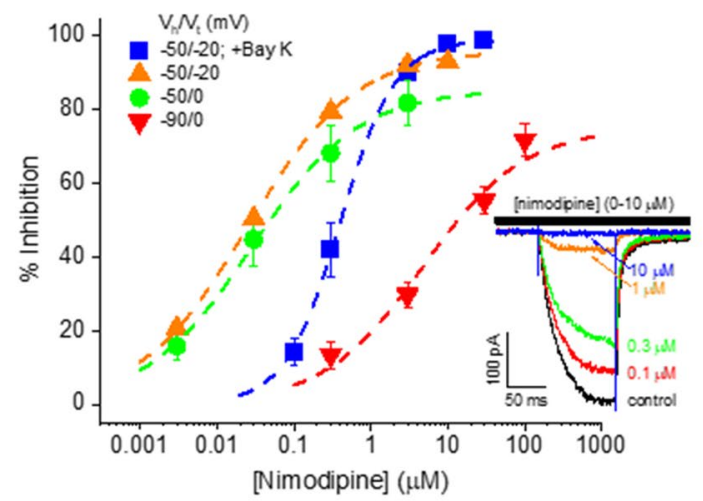

b

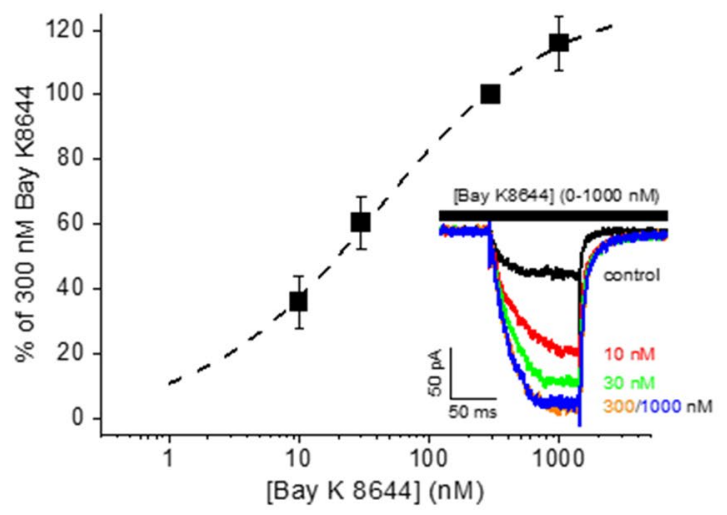

C

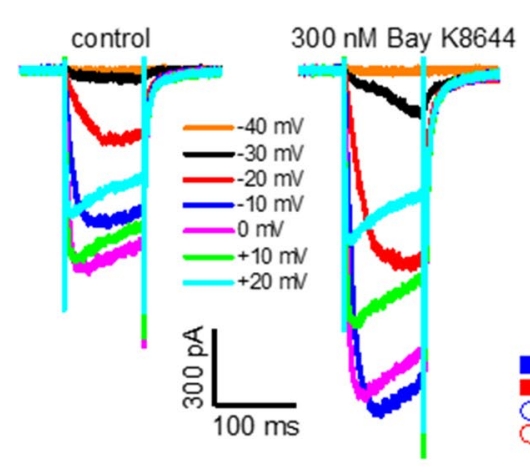

d

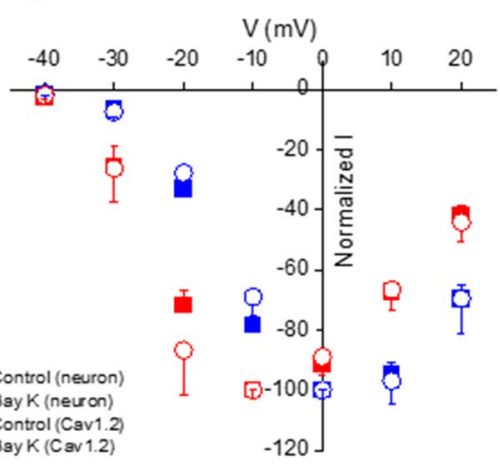

e

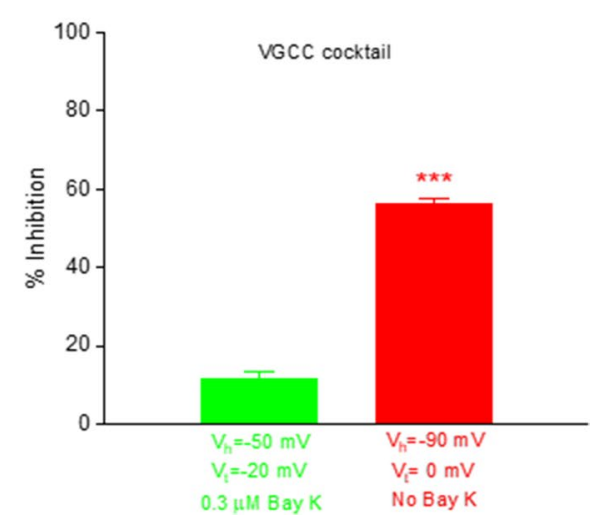

Figure 5. Patch clamp recordings from rat cortical neurons. (a) Nimodipine concentration dependence in the absence and presence of $300 \mathrm{nM}$ Bay K8644. $\mathrm{V}_{\text {hold }}\left(\mathrm{V}_{\mathrm{h}}\right)$ and $\mathrm{V}_{\text {test }}\left(\mathrm{V}_{\mathrm{t}}\right)$ are as indicated. $\mathrm{IC}_{50} / \mathrm{max}$ \%inhibition from the best fits (dashed lines) are: $28.3 \pm 6.5 \mathrm{nM} / 85.4 \pm 3.7 \%(-50 / 0 \mathrm{mV}$, control, $\mathrm{n}=4), 24.8 \pm 1.3 \mathrm{nM} / 96.1 \pm 0.8 \%$, $(-50 /-20 \mathrm{mV}$, control, $\mathrm{n}=4), 400.7 \pm 21.8 \mathrm{nM} / 99.1 \pm 1.1 \%(-50 /-20 \mathrm{mV}, 300 \mathrm{nM}$ Bay $\mathrm{K}, \mathrm{n}=7)$, and $4.8 \pm 1.4 \mu \mathrm{M} / 75 \%(-90 / 0 \mathrm{mV}$, control, $\mathrm{n}=4)$, respectively. Inset: Current traces for $-50 /-20 \mathrm{mV}$ with $300 \mathrm{nM}$ Bay K. (b) Bay K8644 concentration dependence. $\mathrm{EC}_{50}=40.6 \mathrm{nM}$ from the best fit (dashed line; $\mathrm{n}=7$ ). $\mathrm{V}_{\text {hold }}=-$ $50 \mathrm{mV}$ and $\mathrm{V}_{\text {test }}=-20 \mathrm{mV}$. Inset: Current traces. (c) Current traces from the same neuron in response to a series of step voltage changes (from $-40 \mathrm{mV}$ to $+20 \mathrm{mV}$ ) in the absence (left panel) and presence (right panel) of $300 \mathrm{nM}$ Bay K8644. The holding potential was $-50 \mathrm{mV}$. (d) Normalized I-V plots from multiple neurons (solid symbols) and CHOs expressing $\mathrm{Ca}_{\mathrm{V}} 1.2$ (open symbols) in the absence (blue symbols; normalized to the peak current amplitude at $0 \mathrm{mV}$ for each cell before averaging; $\mathrm{n}=27$ and 8 , respectively) and presence (red symbols; normalized to the peak current amplitude at $-10 \mathrm{mV}$ for each cell before averaging; $\mathrm{n}=17$ and 6 , respectively) of $300 \mathrm{nM}$ Bay K8644. The holding potential was $-50 \mathrm{mV}$ for both neurons and CHOs. (e) A cocktail of peptidic blockers of VGCCs (but not of LTCCs) (200 nM $\omega$-agatoxin IVA for P-type, $1 \mu \mathrm{M} \omega$-conotoxin GVIA for N-type, $1 \mu \mathrm{M} \omega$-conotoxin MVIIC for N-, P- and Q-types and $30 \mathrm{nM}$ SNX-482 for R-type, respectively) had minimal effect on $\mathrm{Ba}^{2+}$ currents recorded under conditions favoring LTCC activation $(11.3 \pm 2.1 \%$ inhibition, $\mathrm{n}=3$; left bar), but blocked a significantly higher fraction of the total current under conditions activating all VGCCs (56.1 $\pm 1.7 \%$ inhibition, $\mathrm{n}=6$; right bar; $\mathrm{p}<0.001$, two-tailed Student's t-test).

of Bay K and use of the $-50 /-20 \mathrm{mV}$ voltage protocol together enabled the isolation/recording of virtually pure LTCC currents from cortical neurons.

Confirmation of primary hits in patch clamp. Using the patch clamp assay validated above, we tested niclosamide and cyproheptadine, the two non-DHPs hits in Table 1. In rat cortical neurons, $3 \mu \mathrm{M}$ cyproheptadine blocked $75.2 \pm 9.1 \%(n=4)$ of the LTCC currents, in line with its binding affinities to the DHP, phenylalkylamine and benzothiazepine sites (Table 1). In contrast, while niclosamide potently blocked neuronal LTCC currents $\left(\mathrm{IC}_{50}=183.1 \pm 28.2 \mathrm{nM}, \mathrm{n}=6\right.$; Fig. $\left.6 \mathrm{a}, \mathrm{c}\right)$, it showed no binding at any of these sites in rat cortical preparations $\left(\mathrm{K}_{\mathrm{i}}>30 \mu \mathrm{M}\right.$ for all three sites; $\mathrm{n}=4$; also see Table 1$)$, suggesting that niclosamide binds to a novel site in the LTCC channel complex in neurons. Similar to control, the I-V curve in the presence of niclosamide (200 nM) peaked near $-20 \mathrm{mV}$, although niclosamide block was more pronounced at depolarized potentials (Fig. $6 \mathrm{~d}$ ). The activation and inactivation kinetics in the presence of niclosamide were not significantly different from control. The $20-80 \%$ rise time $($ at $-20 \mathrm{mV})$ was $17.4 \pm 2.9 \mathrm{~ms}(\mathrm{n}=5)$ and $16.1 \pm 3.5 \mathrm{~ms}(\mathrm{n}=4)$ in the absence and presence 

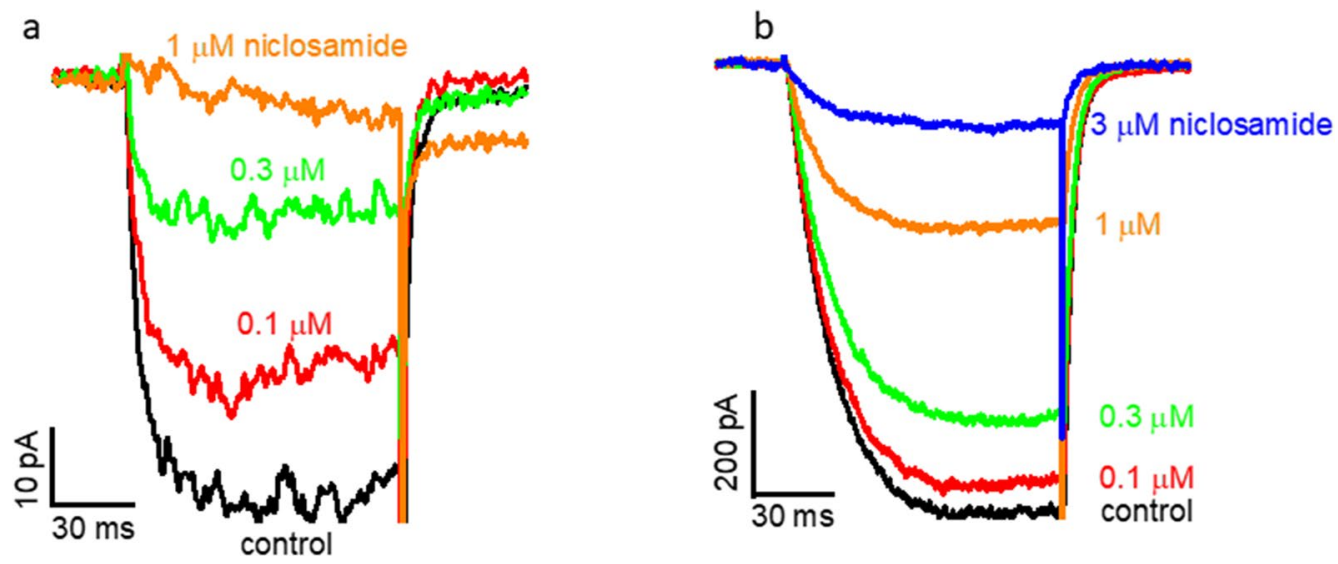

C
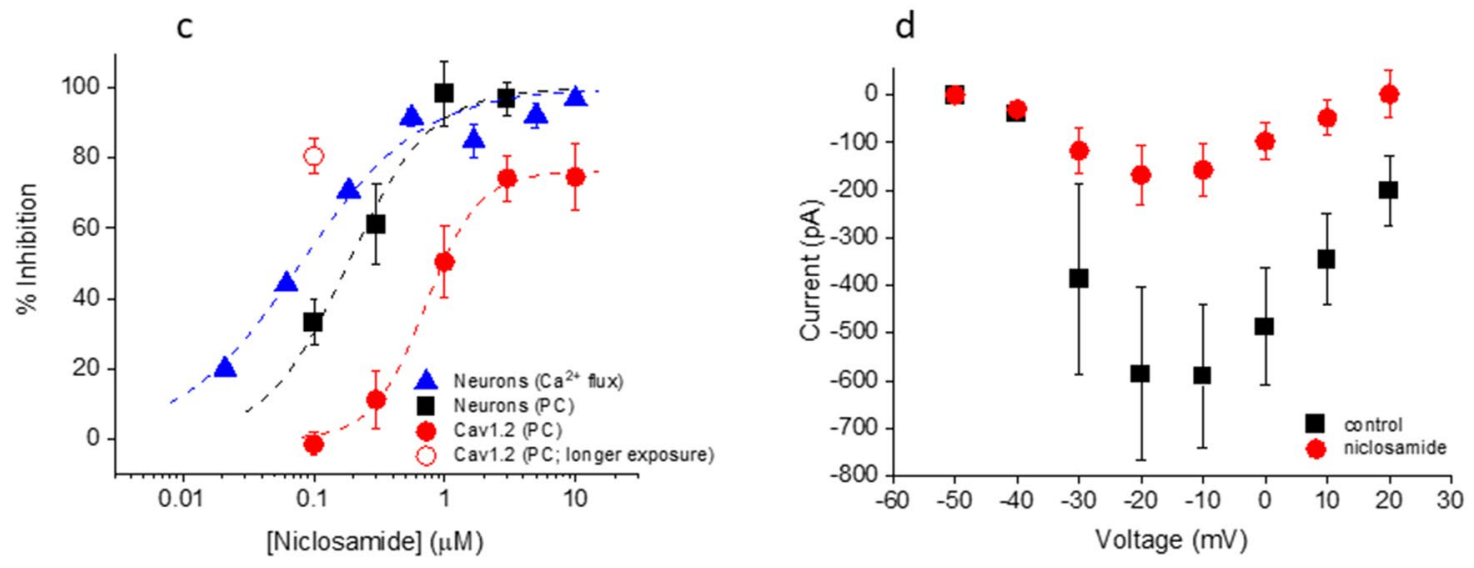

Figure 6. Effect of niclosamide on LTCC currents from rat cortical neurons and $\mathrm{Ca}_{\mathrm{V}} 1.2$ currents in $\mathrm{CHO}$ cells (a) Current traces from a neuron in the absence and presence of niclosamide. (b) Current traces from a Ca $\mathrm{Ca}_{\mathrm{V}} 1.2-$ expressing $\mathrm{CHO}$ in the absence and presence of niclosamide. (c) Concentration-dependent inhibition of LTCCmediated calcium flux in cortical cultures (solid triangles; $\mathrm{IC}_{50}=79.5 \pm 12.8 \mathrm{nM}$; maximal \% inhibition $=100 \%$; $\mathrm{n}=3$ ), LTCC currents recorded from cortical neurons (solid squares; $\mathrm{IC}_{50}=183.1 \pm 28.2 \mathrm{nM}$; maximal \% inhibition $=100 \% ; n=6$ ) and $\mathrm{Ca}_{\mathrm{V}} 1.2$-expressing $\mathrm{CHO}$ cells (solid circles; $\mathrm{IC}_{50}=715.3 \pm 49.2 \mathrm{nM}$; maximal \% inhibition $=76.1 \pm 2.0 \% ; \mathrm{n}=7$; $\mathrm{p}<0.001$ vs neurons, two-way ANOVA). At $100 \mathrm{nM}$ niclosamide, inhibition of $\mathrm{Ca}_{\mathrm{V}} 1.2$ was significantly greater when $\mathrm{CHO}$ cells were exposed to the compound for longer periods (open circle, $80.6 \pm 4.9 \%, \mathrm{n}=4$ ) than that of LTCCs in neurons (solid squares; $\mathrm{p}<0.001$, one-way ANOVA) or that of $\mathrm{Ca}_{\mathrm{V}} 1.2$ when $\mathrm{CHO}$ cells were exposed to the compound for shorter periods (solid circles; $\mathrm{p}<0.001$, one-way ANOVA). All patch clamp experiments were performed in the presence of $300 \mathrm{nM}$ Bay K8644 at a holding potential of $-50 \mathrm{mV}$ and test potential of $-20 \mathrm{mV}$. (d) I-V plots in the absence (squares) and presence (circles) of $200 \mathrm{nM}$ niclosamide (from the same 5 neurons). The holding potential was $-50 \mathrm{mV}$. A cocktail of VGCC blockers, SNX-482 (30 nM), Ф-agatoxin IVA $(200 \mathrm{nM})$, ๑-conotoxin GVIA $(1 \mu \mathrm{M})$ and $₫$-conotoxin MVIIC $(1 \mu \mathrm{M})$, was present in the extracellular solution.

of $200 \mathrm{nM}$ niclosamide, respectively ( $\mathrm{p}>0.7$ ). The current remaining after $400 \mathrm{~ms}$ of depolarization to $-20 \mathrm{mV}$ was $41.9 \pm 7.5 \%(n=4)$ of the peak in niclosamide vs $49.1 \pm 3.4 \%(n=5)$ in control $(p>0.3)$. Both compounds also blocked $\mathrm{Ca}_{\mathrm{V}} 1.2$ currents in CHO cells $\left(\mathrm{IC}_{50}=715.3 \pm 49.2 \mathrm{nM}\right.$ for niclosamide, $\mathrm{n}=7$, Fig. $6 \mathrm{~b}, \mathrm{c} ; 52.3 \pm 6.1 \%$ inhibition at $3 \mu \mathrm{M}$ for cyproheptadine, $\mathrm{n}=3$ ). Niclosamide blocked $\mathrm{Ca}_{\mathrm{V}} 1.2$ expressed in CHO cells with lower potency (by fourfold) and efficacy (76.1\%) than for neuronal LTCCs (full efficacy). Surprisingly, niclosamide block of Cav1.2 (100 nM) was more pronounced in experiments in which niclosamide was applied for significantly longer durations (average of $\sim 6.5 \mathrm{~min}$ ) than those used for $\mathrm{Ca}_{\mathrm{V}} 1.2$ concentration-response experiments (average $\sim 3.5 \mathrm{~min}$ ) (Fig. 6c). Though not corrected for current rundown, this extra block was not due to compoundindependent current rundown, which was only $8.4 \pm 3.7 \%$ and $12.4 \pm 7.6 \%$, respectively, after 3.5 and $6.5 \mathrm{~min}$ in compound-free buffer $(n=4)$.

\section{Discussion}

In an effort to identify novel, neuro-selective LTCC blockers, we took a phenotypic approach and developed two assays using rat primary cortical cultures: a medium-throughput, calcium flux-based fluorescence assay and a patch clamp, secondary confirmation assay.

We optimized the assays by using Bay K8644, a LTCC-selective agonist, along with a moderately elevated $\left[\mathrm{K}^{+}\right]$in the extracellular incubating buffer $(20 \mathrm{mM}$; the calcium flux assay) or moderately depolarized holding 
potential (- $50 \mathrm{mV}$; the patch clamp assay). This combination selectively amplified LTCC responses with minimal activation of other VGCCs. We further showed that these protocols resulted in $\mathrm{Ca}^{2+}$ responses or $\mathrm{Ba}^{2+}$ currents specifically through LTCCs rather than non-specific or LTCC-mediated secondary responses. Moreover, the pharmacology of LTCCs using well-documented reference compounds was also in line with the literature.

Brain LTCCs comprise $\mathrm{Ca}_{\mathrm{V}} 1.2$ and $\mathrm{Ca}_{\mathrm{V}} 1.3$, with the former being the dominant isoform ${ }^{38}$. While it is tempting to speculate that responses in our assays primarily reflect $\mathrm{Ca}^{2+} / \mathrm{Ba}^{2+}$ influx through $\mathrm{Ca}_{\mathrm{V}} 1.2$, it is not possible to estimate the relative contributions of these isoforms based on our data.

We conducted a pilot screen of 1278 known bioactive agents from the PW library using the calcium flux assay. The results of the screen validated our assay in several ways. First, the assay was robust as suggested by (1) a good correlation $\left(r^{2}=0.62\right)$ between the two independent runs of the screen, (2) a hit confirmation rate of $80 \%$ in a concentration-dependent manner, and (3) a Z' value of $\sim 0.5$. Second, most of the DHP drugs in the library $(\sim 83 \%)$, which are all potent LTCC blockers, were correctly identified in the screen. They were all among and represented $50 \%$ of the top 20 most potent hits. Third, six of the 10 non-DHPs in the top 20 hits have been reported as LTCC blockers in the literature. The only two non-DHPs in the top 10 hits were both confirmed in the patch clamp assay. One of them, niclosamide, is a novel LTCC blocker identified from our screen for the first time. Independent confirmation of these compounds by patch clamp lent further support for the strength and validity of our primary screening assay.

Combining the literature information and our patch clamp results for the top 20 most potent hits, an upper limit can be placed for the false positive rate associated with the screen. Since no literature information on LTCC effects is available for 3 of the 20 hits (the 4 th, niclosamide, was positively confirmed by our patch clamp assay), the false positive rate could be up to $15 \%(3 / 20)$ assuming all three are false positives. It should be cautioned, however, that this estimate could be less reliable when extrapolated to a larger-scale screen because of (1) the relatively small data set in this study and (2) the nature of the extrapolation, i.e., largely from one known mechanism, DHP block of LTCCs, to potentially different and/or novel mechanisms by which many hits cause apparent inhibition.

It should be noted that it is intrinsically a higher hurdle to demonstrate that a hit in our primary assay (or any phenotypic screen) is a false positive since negative outcomes (i.e., failure to confirm a hit) in confirmation assays using recombinant $\mathrm{Ca}_{\mathrm{V}} 1.2$-expressing systems do not necessarily prove that a hit is a false positive. After all, our phenotypic assay is intended for identifying neuro-selective or otherwise mechanistically novel LTCC antagonists, which may well be inactive at recombinant $\mathrm{Ca}_{\mathrm{V}} 1$-2-expressing cells if, for instance, the target protein that a hit binds to is not expressed in the recombinant system. Nor is lack of displacement binding, even in the same neuronal preps, indicative of false positivity as the compound may bind to a different site than the tracer used (as illustrated for niclosamide in this study). Therefore, it is critical to verify primary hits from a phenotypic screen by an independent, preferably functional assay (e.g., patch clamp) in a native environment.

Using cortical neurons prepared the same way as for the calcium flux assay, we developed and validated a manual patch clamp assay for hit confirmation. The patch clamp assay confirmed both non-DHPs in the top 10 primary hits, niclosamide and cyproheptadine. Of particular interest, niclosamide has not been noted in the literature for its actions at LTCCs. Combining patch clamp with binding studies, we showed that niclosamide bound to a novel site in neuronal LTCCs with at least two orders of magnitude higher affinity than that at the DHP, phenylalkylamine and benzothiazepine sites. Future studies will be necessary to characterize the novel binding site and molecular mechanism of niclosamide.

In summary, we have developed and validated two phenotypic assays that have promising potential for identifying mechanistically novel and neuro-selective LTCC blockers in large-scale screening campaigns.

\section{Methods}

Neuronal cultures. Rat cortical neurons were isolated from E-18 Sprague-Dawley rats as previously described $^{39}$ (BrainBits, Springfield, IL). Briefly, cortices were isolated, rapidly removed from decapitated pups, and stored in ice-cold Hibernate-E media. Cortices were then transferred into a $15 \mathrm{~mL}$ conical tube and incubated at $37^{\circ} \mathrm{C}$ for $10 \mathrm{~min}$ in $2 \mathrm{~mL}$ papain dilution buffer containing $5 \mathrm{mM} \mathrm{L}$-cysteine, $1 \mathrm{mM}$ EDTA, $10 \mathrm{mM}$ HEPES, $100 \mu \mathrm{g} / \mathrm{mL}$ BSA, $1 \%$ papain and $0.1 \%$ DNase I. Heat-inactivated FBS $(2 \mathrm{~mL})$ and additional DNase I $(5 \mu \mathrm{L})$ were added at the end of the incubation period after which cells were mechanically dissociated until homogeneous using a $10 \mathrm{~mL}$ pipette and centrifuged (5 min at $1000 \mathrm{rpm}$ at room temperature). The cell pellet was then resuspended in culture media containing neurobasal medium supplemented with B27 and $0.5 \mathrm{mM}$ Glutamax. Resuspended cells were centrifuged and the pellet was resuspended again in culture media. Finally, cells were filtered using a $70 \mu \mathrm{m}$ cell strainer, centrifuged, resuspended in culture media, and plated in Falcon 384-well black wall, clear bottom plates (for the calcium flux assay) or on poly-D-Lysine coated glass coverslips (for the patch clamp assay). Cortical cultures were placed in a $37{ }^{\circ} \mathrm{C}$ humidified incubator maintained at $5 \%$ $\mathrm{CO}_{2}$. One half of the culture media was replaced with fresh media 5 days after plating. Animal protocols were approved by the Institutional Animal Care and Use Committee of Janssen Research \& Development, L.L.C. All experiments were performed in accordance with the relevant guidelines and regulations.

Recombinant cell cultures. The tetracycline-inducible human $\mathrm{Ca}_{\mathrm{V}} 1.2 \alpha 1$ subunit was stably co-expressed in CHO cells with human $\beta 2 \mathrm{a}$ and human a $2 \delta 1$ subunits (with GenBank accession numbers NM_000719.4, NM_000724.2, and NM_000722.2, respectively; Charles River, Cleveland, OH). The CHO cells also stably expressed hKir2.2. Cells were cultured in Ham's F12, supplemented with $10 \%$ FBS, $1 \%$ penicillin-streptomycin, $0.01 \mathrm{mg} / \mathrm{mL}$ blasticidin, $0.25 \mathrm{mg} / \mathrm{mL} \mathrm{G} 418,0.25 \mathrm{mg} / \mathrm{mL}$ hygromycin, and $0.4 \mathrm{mg} / \mathrm{mL}$ zeocin. and incubated at $37^{\circ} \mathrm{C}$ with $5 \% \mathrm{CO}_{2}$. Cells were induced with $1 \mu \mathrm{g} / \mathrm{mL}$ tetracycline in selection antibiotic-free media the day before use. 
Calcium flux assay. The assay buffer contained $137 \mathrm{mM} \mathrm{NaCl}, 20 \mathrm{mM} \mathrm{KCl}, 10 \mathrm{mM}$ HEPES, $5 \mathrm{mM}$ glucose, $2 \mathrm{mM} \mathrm{CaCl}_{2}, 1 \mathrm{mM} \mathrm{MgCl}_{2}$, at $\mathrm{pH}$ 7.4. For experiments in which the $\mathrm{KCl}$ concentration was varied, the concentration of $\mathrm{NaCl}$ was adjusted accordingly to maintain a constant total salt concentration. The cocktail used to inhibit the network activity contained $0.1 \mu \mathrm{M}$ tetrodotoxin (TTX), $10 \mu \mathrm{M}$ picrotoxin, $50 \mu \mathrm{M} \mathrm{D}$-(-)-2-Amino5-phosphonopentanoic acid (AP5) and $5 \mu \mathrm{M}$ 2,3-Dioxo-6-nitro-1,2,3,4-tetrahydrobenzo[f] quinoxaline-7-sulfonamide (NBQX).

Assay development experiments were conducted using DIV11-21 primary cultures at a density of 12-24 K/ well, for which Bay K-induced responses did not vary widely. The PW library screen was performed using DIV 12 cultures, with a density of $12 \mathrm{~K} /$ well. Bay K8644 $(1.1 \mu \mathrm{M})$ and nimodipine $(3 \mu \mathrm{M})$ were used as positive and negative controls, respectively. Cells were first washed $3 \times$ with $85 \mu \mathrm{L}$ assay buffer using the ELX-405 plate washer, ending with $25 \mu \mathrm{L}$ buffer in each well. Then, $25 \mu \mathrm{L}$ of $1 \times$ Calcium 6 no-wash dye was added to each well using a Multidrop and incubated at room temperature for $1 \mathrm{~h}$. Next, $25 \mu \mathrm{L}$ of $6 \times$ compound prepared in cocktail assay buffer was added and incubated for $30 \mathrm{~min}$ at room temperature. The compound concentration during incubation was $2 \times$. The plates were aspirated, leaving $25 \mu \mathrm{L} /$ well. Finally, assay plates were transferred to FLIPR (Molecular Devices, Sunnyvale, CA) for a 30 s baseline read followed by addition of $2 \times$ Bay K $8644(2.2 \mu \mathrm{M})$. The total recording time was $180 \mathrm{~s}$ at $1 \mathrm{~Hz}$. Control wells contained either $1.1 \mu \mathrm{M}$ Bay K8644 or 1.1 $\mu \mathrm{M}$ Bay K8644 plus $3 \mu \mathrm{M}$ nimodipine. For the PW library screen, all wells contained either $0.15 \%$ ( $3 \mu \mathrm{M}$ single concentration screen) or $0.3 \%$ (concentration-response confirmation of hits) DMSO. In experiments involving peptidic blockers of VGCCs, $0.1 \%$ BSA was included in all buffers.

Electrophysiology. Patch clamp recordings were conducted at room temperature $\left(\sim 22^{\circ} \mathrm{C}\right)$. Whole-cell currents were measured using pClamp 10 software (Molecular Devices) and Axopatch 200B amplifier, lowpass filtered at $2 \mathrm{kHz}$ and digitized at $10 \mathrm{kHz}$. The series resistance was $75 \%$ compensated. In the optimized assay, currents were elicited by depolarization to $-20 \mathrm{mV}(100 \mathrm{~ms})$ from a holding potential of $-50 \mathrm{mV}$ once every $20 \mathrm{~s}$ in the constant presence of $300 \mathrm{nM}$ Bay K8644 and allowed to stabilize in both control buffer and compound applications (for $\sim 3 \mathrm{~min}$ ). Compounds were perfused using a SF-77B Fast-Step Perfusion device (Warner Instruments).

DIV5-14 neurons on $35 \mathrm{~mm}$ glass coverslips (1-3 $\times 10^{5} /$ coverslip) or freshly dissociated and tetracyclineinduced (for 24-48 h) CHO cells co-expressing human L-type calcium channel $\alpha_{1 \mathrm{C}}\left(\mathrm{Ca} \mathrm{a}_{\mathrm{V}} 1.2\right), \beta_{2 \mathrm{a}}$, and $\alpha_{2} \delta_{1}$ subunits were placed in a chamber on the stage of an inverted microscope and perfused $(\sim 1 \mathrm{~mL} / \mathrm{min})$ with an extracellular solution containing: $149 \mathrm{mM}$ choline chloride, $5 \mathrm{mM} \mathrm{BaCl}_{2}, 1 \mathrm{mM} \mathrm{MgCl}_{2}, 5 \mathrm{mM}$ glucose, $10 \mathrm{mM}$ HEPES, at pH 7.4 and 310 mosM/L. Pipette electrodes were filled with an intracellular solution of the following composition: $115 \mathrm{mM}$ Cs methanesulfonate, $20 \mathrm{mM} \mathrm{CsCl}, 4 \mathrm{mM} \mathrm{MgATP}, 0.3 \mathrm{mM} \mathrm{Na}_{2} \mathrm{GTP}, 10 \mathrm{mM}$ EGTA and $20 \mathrm{mM}$ HEPES, at pH 7.2 and 295 mosM/L. In experiments involving peptidic blockers of VGCCs, $0.1 \%$ BSA was included in all extracellular buffers.

Binding studies. The in-vitro binding studies were conducted by Eurofins (France) using rat cortex. The radio ligands and incubation (at room temperature) times used for the DHP, benzothiazepine and phenylalkylamine sites were $\left[{ }^{3} \mathrm{H}\right]$ nitrendipine $(0.1 \mathrm{nM} ; 90 \mathrm{~min}),\left[{ }^{3} \mathrm{H}\right]$ diltiazem $(15 \mathrm{nM} ; 120 \mathrm{~min})$ and $\left[{ }^{3} \mathrm{H}\right] \mathrm{D} 888(3 \mathrm{nM}$; $120 \mathrm{~min}$ ), respectively. The amount of protein/assay were $150 \mu \mathrm{g}, 300 \mu \mathrm{g}$ and $200-300 \mu \mathrm{g}$, respectively. The ratio of specific over non-specific binding signals was 9.1-15.1, 2.8-3.5 and 5.1-7.8, respectively. Nitrendipine $(1 \mu \mathrm{M})$, diltiazem $(10 \mu \mathrm{M})$ and D600 $(10 \mu \mathrm{M})$, respectively, were used for evaluations of non-specific binding and as positive controls with $\mathrm{IC}_{50}$ values of $0.19 \pm 0.03 \mathrm{nM}, 42.7 \pm 6.8 \mathrm{nM}$ and $26.8 \pm 3.6 \mathrm{nM}$, respectively $(\mathrm{n}=4)$.

Chemicals. TTX was obtained from Alamone (Israel). The PW chemical library was from Prestwick Chemical (France) and contained 1278 small molecular-weight drugs or otherwise bioactive agents. All other reference compounds were from Tocris.

Data analysis. For the calcium flux assay, the peak Bay K-induced change in fluorescence from baseline, $\mathrm{R}$, was used to calculate the \% inhibition value as follows: $\mathrm{R}=100^{*}(\mathrm{P}-\mathrm{R}) /(\mathrm{P}-\mathrm{N})$, where $\mathrm{P}$ and $\mathrm{N}$ are the peak responses in Bay $\mathrm{K}$ alone and Bay $\mathrm{K}+$ nimodipine, respectively. Compounds that substantially altered the baseline fluorescence in either direction $(\geq \pm 30 \%)$ were excluded before hit confirmation. For $\mathrm{IC}_{50}$ determination, concentration-response data were fitted to a logistic function of the form: $R=\left(A_{1}-A_{2}\right) /\left(1+\left(C / I C_{50}\right)^{\mathrm{h}}\right)+A_{2}$, where $\mathrm{R}$ was the normalized response, $\mathrm{C}$ was the compound concentration, $\mathrm{IC}_{50}$ was the concentration at which half-maximal response occurred, $\mathrm{h}$ was the Hill coefficient, and A1 and A2 were constants. To evaluate screen robustness, the $Z^{\prime}$ value was calculated as follows: $Z^{\prime}=1-\left(3^{\star} \operatorname{SD}_{\text {positive }}+3^{\star} \mathrm{SD}_{\text {negative }}\right) /\left(\right.$ mean $_{\text {positive }}-$ mean $\left._{\text {negative }}\right)$, where $\mathrm{SD}$ is the standard deviation and positive and negative refer to Bay $\mathrm{K}$ alone and Bay $\mathrm{K}+$ nimodipine, respectively. Statistical analyses were performed using two-tailed Student's t-test or one- or two-way ANOVA with post-hoc Tukey test as indicated.

The percent inhibition data from the PW screen were fitted to a Gaussian function of the form: $y=y_{0}+A$ / $\left(\mathrm{w}^{\star} \operatorname{sqrt}(\pi)\right)^{\star} \exp \left(-2^{\star}\left(\mathrm{x}-\mathrm{x}_{\mathrm{c}}\right)^{2} / \mathrm{w}^{2}\right)$, with fitting parameters $\mathrm{y}_{0}$ as the offset (fixed to zero), A as the area under the curve, $x_{c}$ as center of the peak, and $w(=2.35 \mathrm{SD})$ as the full width at half maximum (FWHM).

For patch clamp, leak currents were subtracted using a $\mathrm{p} / 4$ protocol. For I-V curves, test voltage-evoked peak currents were normalized for each cell before averaging. Concentration-response data were fitted to the same logistic function as for the calcium flux data. Data recorded from $n$ different cells were reported as mean \pm SEM. Methods of statistical tests were indicated in figure legends. Data fitting and statistical analysis above were performed using Origin v.9 (Originlab, Northampton, MA). 
For binding experiments, results were expressed (1) as percent of control specific binding: $100 \times$ (measured specific binding/control specific binding) or (2) as percent inhibition of control specific binding in the presence of the test compounds:100-100 $\times$ (measured specific binding/control specific binding). The $\mathrm{IC}_{50}$ values (the concentration that causes half-maximal inhibition of control specific binding) were determined by non-linear regression analysis of the competition curves using Hill equation: $\mathrm{Y}=\mathrm{D}+(\mathrm{A}-\mathrm{D}) /\left[1+\left(\mathrm{C} / \mathrm{IC}_{50}\right)\right]^{\mathrm{nH}}$, where $\mathrm{Y}=$ specific binding, $\mathrm{A}=$ left asymptote of the curve, $\mathrm{D}=$ right asymptote of the curve, $\mathrm{C}=$ compound concentration, and $\mathrm{nH}=$ slope factor. Analyses were performed using software developed at Eurofins (Hill software) and validated by comparison with data generated by the commercial software SigmaPlot 4.0. The inhibition constants $\left(\mathrm{K}_{\mathrm{i}}\right)$ were calculated using the Cheng Prusoff equation $\mathrm{K}_{\mathrm{i}}=\mathrm{IC}_{50} \times\left(1+\mathrm{L} / \mathrm{K}_{\mathrm{D}}\right)$, where $\mathrm{L}=$ concentration of radioligand in the assay and $\mathrm{K}_{\mathrm{D}}=$ affinity of the radioligand for the receptor. $\mathrm{K}_{\mathrm{D}}$ values were determined from Scatchard plots.

\section{Data availability}

The datasets generated and/or analyzed during the current study are available from the corresponding author on reasonable request.

Received: 24 July 2020; Accepted: 22 December 2020

Published online: 11 January 2021

\section{References}

1. Striessnig, J., Pinggera, A., Kaur, G., Bock, G. \& Tuluc, P. L-type Ca2+ channels in heart and brain. Wiley Interdiscip. Rev. Membr. Transp. Signal. 3, 15-38 (2014).

2. Marcantoni, A., Calorio, C., Hidisoglu, E., Chiantia, G., Carbone E. Cav1.2 channelopathies causing autism: new hallmarks on Timothy syndrome. Pflügers Archiv - European Journal of Physiology 472, 775-789 (2020).

3. Ortner, N. J., Kaserer, T., J., Copeland, N. \& Striessnig, J. De novo CACAN1D Ca ${ }^{2+}$ channelopathies: clinical phenotypes and molecular mechanism. Pflügers Archiv - European Journal of Physiology 472, 755-773 (2020).

4. Nanou, E. \& Catterall, W. A. Calcium channels, synaptic plasticity, and neuropsychiatric disease. Neuron 98, 466-481 (2018).

5. Liss, B. \& Striessnig, J. The potential of L-type calcium channels as a drug target for neuroprotective therapy in Parkinson's disease. Annu. Rev. Pharmacol. Toxicol. 59, 263-289 (2019).

6. Ortner, N. J. \& Striessnig, J. L-type calcium channels as drug targets in CNS disorders. Channels (Austin). 10, 7-13 (2016).

7. Cipriani, A. et al. A systematic review of calcium channel antagonists in bipolar disorder and some considerations for their future development. Mol. Psychiatry. 21, 1324-1332 (2016).

8. Hering, S., Berjukow, S., Acze'1, S. \& Timin, E. N. Calcium channel block and inactivation: common molecular determinants. Trends Pharmacol. Sci. 19, 439-443 (1998).

9. Beyl, S. et al. Probing the architecture of an L-type calcium channel with a charged phenylalkylamine: evidence for a widely open pore and drug trapping. J. Biol. Chem. 282, 3864-3870 (2007).

10. Bean, B. P. Nitrendipine block of cardiac calcium channels: high-affinity binding to the inactivated state. Proc. Natl. Acad. Sci. USA 81, 6388-6392 (1984).

11. Berjukow, S. \& Hering, S. Voltage-dependent acceleration of $\mathrm{Ca}_{\mathrm{V}} 1.2$ channel current decay by (+)- and (-)-isradipine. Br. J. Pharmacol. 133, 959-966 (2001).

12. Liu, G. et al. Mechanism of adrenergic $\mathrm{Ca}_{\mathrm{v}} 1.2$ stimulation revealed by proximity proteomics. Nature $577,695-700$ (2020). https ://doi.org/10.1038/s41586-020-1947-z.

13. Müller, C. S. et al. Quantitative proteomics of the $\mathrm{Ca}_{\mathrm{v}} 2$ channel nano-environments in the mammalian brain. Proc Natl Acad Sci USA 107, 14950-14957 (2010).

14. Zhang, H. et al. Association of Ca 1 1.3 L-type calcium channels with Shank. J. Neurosci. 25, 1037-1049 (2005).

15. Calin-Jageman, I., Yu, K., Hall, R. A., Mei, L. \& Lee, A. Erbin enhances voltage-dependent facilitation of Ca(v) $1.3 \mathrm{Ca} 2+$ channels through relief of an autoinhibitory domain in the Ca(v)1.3 alpha1 subunit. J. Neurosci. 27, 1374-1385 (2007).

16. Calin-Jageman, I. \& Lee, A. Ca $\mathrm{V}_{\mathrm{V}} 1 \mathrm{~L}$-type $\mathrm{Ca}^{2+}$ channel signaling complexes in neurons. J. Neurochem. 105, 573-583 (2008).

17. Lipscombe, D., Allen, S. E. \& Toro, C. P. Control of neuronal voltage-gated calcium ion channels from RNA to protein. Trends Neurosci. 36, 598-609 (2013).

18. Tippens, A. L. \& Lee, A. Caldendrin, a neuron-specific modulator of $\mathrm{Ca}_{\mathrm{V}} 1.2$ (L-type) Ca2+ channels. J. Biol. Chem. 282, 8464-8473 (2007).

19. Oz, S., Tsemakhovich, V., Christel, C. J., Lee, A. \& Dascal, N. CaBP1 regulates voltage-dependent inactivation and activation of $\mathrm{Ca}_{\mathrm{v}} 1.2$ (L-type) calcium channels. J. Biol. Chem. 286, 13945-13953 (2011).

20. Béguin, P. et al. BARP suppresses voltage-gated calcium channel activity and Ca2+-evoked exocytosis. J. Cell Biol. 28, 233-249 (2014).

21. Wang, S. et al. Densin-180 Controls the Trafficking and Signaling of L-Type Voltage-Gated Ca v 1.2 Ca 2+ Channels at Excitatory Synapses. J. Neurosci. 37, 4679-4691 (2017).

22. Polster, A. et al. Stac Proteins Suppress Ca2+-Dependent Inactivation of Neuronal l-type Ca2+ Channels. J. Neurosci. 38, 9215-9227 (2018).

23. Clark, M. B. et al. Long-read sequencing reveals the complex splicing profile of the psychiatric risk gene CACNA1C in human brain. Mol. Psychiatry 25, 37-47. https://doi.org/10.1038/s41380-019-0583-1 (2020).

24. Zamponi, G. W., Striessnig, J., Koschak, A. \& Dolphin, A. C. The physiology, pathology, and pharmacology of voltage-gated calcium channels and their future therapeutic potential. Pharmacol. Rev. 67, 821-870 (2015).

25. Welling, A. et al. Alternatively spliced IS6 segments of the alpha $1 \mathrm{C}$ gene determine the tissue-specific dihydropyridine sensitivity of cardiac and vascular smooth muscle L-type Ca2+ channels. Circ. Res. 81, 526-532 (1997).

26. Lipscombe, D., Andrade, A. \& Allen, S. E. Alternative splicing: functional diversity among voltage-gated calcium channels and behavioral consequences. Biochim. Biophys. Acta 1828, 1522-1529 (2013).

27. Bechem, M. \& Hoffmann, H. The molecular mode of action of the Ca agonist (-) BAY K 8644 on the cardiac Ca channel. Pflugers Arch. 424, 343-353 (1993).

28. Dilmac, N., Hilliard, N. \& Hockerman, G. H. Molecular Determinants of Ca2+ Potentiation of Diltiazem Block and Ca2+Dependent Inactivation in the Pore Region of $\mathrm{Ca}_{\mathrm{V}} 1.2$. Mol. Pharmacol. 64, 491-501 (2003).

29. Dilmac, N., Hilliard, N. \& Hockerman, G. H. Molecular determinants of frequency dependence and Ca2+ potentiation of verapamil block in the pore region of $\mathrm{Ca}_{\mathrm{V}} 1.2$. Mol. Pharmacol. 66, 1236-1247 (2004).

30. Xia, M., Imredy, J. P., Koblan, K. S., Bennett, P. \& Connolly, T. M. State-dependent inhibition of L-type calcium channels: cell-based assay in high-throughput format. Anal. Biochem. 327, 74-81 (2004).

31. Winquist, R. J. et al. Calcium entry blocker activity of cyproheptadine in isolated cardiovascular preparations. J. Pharmacol. Exp. Ther. 230, 103-109 (1984). 
32. Lacerda, A. E., Kuryshev, Y. A., Yan, G. X., Waldo, A. L. \& Brown, A. M. Vanoxerine: cellular mechanism of a new antiarrhythmic. J. Cardiovasc. Electrophysiol. 21, 301-310 (2010).

33. Kang, J., Chen, X. L., Ji, J., Lei, Q. \& Rampe, D. Ca2+ channel activators reveal differential L-type Ca2+ channel pharmacology between native and stem cell-derived cardiomyocytes. J. Pharmacol. Exp. Ther. 341, 510-517 (2012).

34. King, V. F., Garcia, M. L., Shevell, J. L., Slaughter, R. S. \& Kaczorowski, G. J. Substituted diphenylbutylpiperidines bind to a unique high affinity site on the L-type calcium channel. Evidence for a fourth site in the cardiac calcium entry blocker receptor complex. J. Biol. Chem. 264, 5633-5641 (1989).

35. Nawrath, H., Klein, G., Rupp, J., Wegener, J. W. \& Shainberg, A. Open state block by fendiline of L-type Ca++ channels in ventricular myocytes from rat heart. J. Pharmacol. Exp. Ther. 285, 546-552 (1998).

36. Zahradník, I., Minarovic, I. \& Zahradníková, A. Inhibition of the cardiac L-type calcium channel current by antidepressant drugs. J. Pharmacol. Exp. Ther. 324, 977-984 (2008).

37. Zahradníková, A., Minarovic, I. \& Zahradník, I. Competitive and cooperative effects of Bay K8644 on the L-type calcium channel current inhibition by calcium channel antagonists. J. Pharmacol. Exp. Ther. 322, 638-645 (2007).

38. Sinnegger-Brauns, M. J. et al. Expression and 1,4-dihydropyridine-binding properties of brain L-type calcium channel isoforms. Mol Pharmacol. 75, 407-414 (2009).

39. Liu, Y., Hagan, R. \& Schoellerman, J. Dual actions of Psalmotoxin at ASIC1a and ASIC2a heteromeric channels (ASIC1a/2a). Sci. Rep. 8, 7179; https://doi.org/10.1038/s41598-018-25386-9 (2018).

\section{Author contributions}

R.H. developed the fluorescence assay and analyzed the data, maintained the recombinant cell line and neuronal cultures as well as helped generate the recombinant cell line. D.W., M.M., R.H. T.G., E.R. and M.P.M. carried out the PW library screen and/or data analysis/interpretation. Y.L. conceived and designed the fluorescence and electrophysiology assays, carried out and analyzed the patch clamp studies. Y.L. wrote the manuscript. All authors reviewed/edited the manuscript.

\section{Competing interests}

At the time of the work described in this manuscript, all authors were employed by Janssen Research \& Development, LLC, a division of Johnson \& Johnson, the funder of this study.

\section{Additional information}

Supplementary Information The online version contains supplementary material available at https:/doi. org/10.1038/s41598-020-80692-5.

Correspondence and requests for materials should be addressed to Y.L.

Reprints and permissions information is available at www.nature.com/reprints.

Publisher's note Springer Nature remains neutral with regard to jurisdictional claims in published maps and institutional affiliations.

Open Access This article is licensed under a Creative Commons Attribution 4.0 International License, which permits use, sharing, adaptation, distribution and reproduction in any medium or format, as long as you give appropriate credit to the original author(s) and the source, provide a link to the Creative Commons licence, and indicate if changes were made. The images or other third party material in this article are included in the article's Creative Commons licence, unless indicated otherwise in a credit line to the material. If material is not included in the article's Creative Commons licence and your intended use is not permitted by statutory regulation or exceeds the permitted use, you will need to obtain permission directly from the copyright holder. To view a copy of this licence, visit http://creativecommons.org/licenses/by/4.0/.

(C) The Author(s) 2021 